
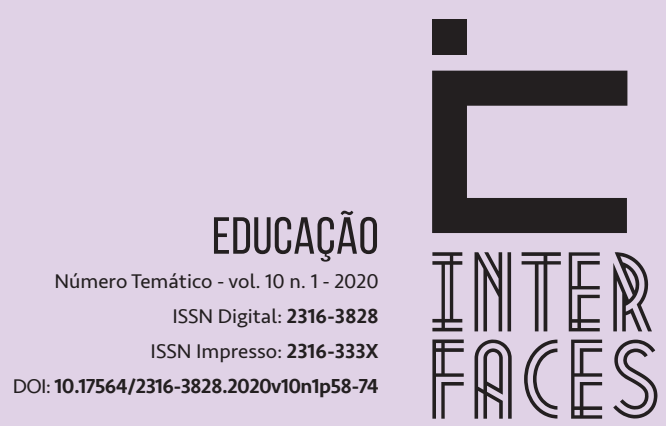

CIENTIIFICAS

\section{COVID-19: DESAFIOS DOS DOCENTES NA LINHA DE FRENTE DA EDUCAÇÃO}

\author{
COVID-19: TEACHERS' CHALLENGES \\ IN THE EDUCATION FRONT LINE
}

COVID-19: DESAFÍOS DE LOS MAESTROS EN LA PRIMERA LIINEA DE LA EDUCACIÓN

Francieli Motter Ludovico ${ }^{1}$ Jaqueline Molon ${ }^{2}$ Sérgio Roberto Kieling Franco ${ }^{3}$ Patrícia da Silva Campelo Costa Barcellos ${ }^{4}$

\section{RESUMO}

A pandemia causada pela Covid-19 exigiu mudanças na organização da sociedade, que precisaram acontecer rapidamente e sem planejamento. Essas novas configurações também influenciaram a educação e levaram as instituições a se reorganizarem, avaliando a possibilidade de ofertar o que está sendo chamado de "Ensino Remoto Emergencial". Esse processo levou os professores, atores na linha de frente da educação, a encontrar muitos e novos desafios. Assim, o presente estudo busca narrar e compreender alguns desafios que estão postos à educação formal frente a este cenário, por meio do relato de nove professores, dos estados do Paraná e do Rio Grande do Sul. Com metodologia qualitativa e modalidade investigativa de análise narrativa, a partir dos processos de codificação e categorização. Três categorias foram elencadas: estratégias de enfrentamento e ferramentas, apoio aos professores e apoio aos pais. Os resultados evidenciam diversos desafios, que vão desde dificuldades de acesso e falta de recursos à necessidade de promover equidade para o desenvolvimento de práticas que incluam todos os estudantes.

\section{PALAVRAS-CHAVE}

Prática Docente. Ensino Remoto Emergencial. Pandemia. Covid 19. 


\section{ABSTRACT}

The Covid-19 pandemic required changes in the organization of society, which needed to happen quickly and without planning. These new configurations also influenced education and led institutions to reorganize themselves, evaluating the possibility of offering what has being called "Emergency Remote Teaching". This process led teachers, actors on the front lines of education, to face many new challenges. Thus, the present study seeks to narrate and understand some challenges that are posed to formal education in this scenario, through the report of nine (09) teachers, from the states of Paraná and Rio Grande do Sul. With qualitative methodology and investigative modality of narrative analysis, based on codification and categorization processes. Three (03) categories were listed: strategies and tools, support for teachers and support for parents. The results show several challenges, ranging from difficulties in access and lack of resources to the need to promote equity for the development of practices that include all students.

\section{KEYWORDS}

Teaching Practice. Emergency Remote Teaching. Pandemic. Covid 19.

\section{RESUMEN}

La pandemia de Covid-19 exigió cambios en la organización de la sociedad, que necesitaron ocurrir rápidamente y sin planificación. Esas nuevas configuraciones también influenciaron a la educación y llevaron a las instituciones a reorganizarse, evaluando la posibilidad de ofrecer lo que se llama "enseñanza remota de emergencia”. Ese proceso ha llevado a los profesores, actores en la línea de frente de la educación, a encontrar muchos desafíos nuevos. De esta manera, el presente estudio busca narrar y comprender algunos desafíos que se encuentran en la educación formal frente a este panorama, por medio del relato de nueve (09) profesores, de los estados de Paraná y Rio Grande do Sul. Con metodología cualitativa y modalidad investigativa de análisis narrativa, a partir de los procesos de codificación y categorización. Se enumeraron tres (03) categorías: estrategias de enfrentamiento y herramientas; apoyo a los profesores y apoyo a los padres. Los resultados muestran varios desafíos, desde dificultades de acceso y falta de recursos hasta la necesidad de promover la equidad para el desarrollo de prácticas que incluyan a todos los estudiantes.

\section{PALABRAS CLAVE}

Práctica docente; Enseñanza remota de emergencia; Pandemia, Covid-19. 


\section{CONSIDERAÇOES INICIAIS}

Tudo que acontece ao nosso redor influencia nossas vidas, visto que pequenas interferências podem gerar grandes mudanças. A pandemia causada pela Covid-19, que chegou ao Brasil no início de 2020, alterou protocolos não somente na área da saúde como também nas demais atividades humanas. O cenário modificou-se, especialmente em função das recomendações da Organização Mundial da Saúde (OMS) (WHO, on-line) no que se refere ao distanciamento físico, medida essencial para achatamento da curva, ou seja, para diminuir a velocidade de contágio, possibilitando o cuidado, pelos sistemas de saúde, a um maior número de pessoas infectadas.

Frente a esse panorama, a educação também foi afetada e, desde então, desafiada a encontrar alternativas para dar continuidade às atividades pedagógicas. Essas foram mudanças que aconteceram do dia para a noite, forçando os professores a aderir ao Ensino Remoto Emergencial (ERE). Desse modo, incide aos professores a responsabilidade pela elaboração de atividades eficazes para a promoção de situações de aprendizagem que possam ser realizadas de forma remota pelos estudantes. Em vista disso, os docentes enfrentam uma série de desafios para a invenção e implementação dessa nova configuração de educação.

Logo, o objetivo do presente artigo é narrar e assim compreender alguns desafios que estão postos à educação formal diante da pandemia de Covid-19 por meio de relatos de professores. Para tanto, esses foram convidados a narrar um pouco desse processo, revelando estratégias, ações ou dificuldades vivenciadas em seus respectivos contextos de atuação. Professores da Educação Básica e da Educação Superior, da rede pública e da rede privada, do interior e das capitais dos estados do Paraná e do Rio Grande do Sul, mesmo sabendo das diferenças na realidade e entre os níveis de educação, buscou-se trazer um panorama com alguns cenários, dessa forma, mostrar desafios e possibilidades.

O estudo inicia com uma discussão teórica sobre as medidas tomadas com a pandemia, recomendações de órgãos como o Conselho Nacional da Educação (CNE), a Organização das Nações Unidas para a Educação, a Ciência e a Cultura (UNESCO) e autores que versam sobre educação, Educação a Distância e o uso de recursos tecnológicos nos processos de ensino e aprendizagem. Na sequência, o percurso metodológico é apresentado. Então, os relatos dos professores, resultados, são apresentados e, por fim, a discussão e a análise das narrativas coletadas são realizadas.

\section{CONTEXTUALIZAÇÕES TEÓRICAS}

O cenário de pandemia implicou na necessidade de adoção de medidas preventivas e de contenção de contágio como o 'distanciamento social', o que pode ser compreendido enquanto distanciamento físico, tendo em vista que uma parte da população continua tendo contatos por meio de mídias sociais e de diferentes Tecnologias Digitais de Informação e Comunicação (TDIC) já utilizadas anteriormente, mas que se tornaram centrais e as principais aliadas para a comunicação entre as pessoas 
durante esse período. No entanto, a pesquisa TIC Domicílios² referente ao ano de 2018, apontou que mais de $30 \%$ dos domicílios brasileiros, cerca de 46,5 milhões, não tinham acesso à internet (TAROUCO, 2019) e pode-se inferir que essa minoria se encontra em distanciamento social.

A necessidade de distanciamento físico impactou diretamente nas atividades das instituições de ensino, da Educação Básica à Educação Superior. Toda a "normalidade" foi alterada. Algumas instituições paralisaram seus calendários letivos, enquanto outras optaram pela continuidade por meio do Ensino Remoto Emergencial (ERE). Não se pode confundir essa estratégia com a modalidade de Educação a Distância (EAD). Conforme definido no artigo $1^{\circ}$ do Decreto n $^{\circ} 9.057$, de 25 de maio de 2017, a EaD caracteriza-se como:

[...] a modalidade educacional na qual a mediação didático-pedagógica nos processos de ensino e aprendizagem ocorra com a utilização de meios e tecnologias de informação e comunicação, com pessoal qualificado, com políticas de acesso, com acompanhamento e avaliação compatíveis, entre outros, e desenvolva atividades educativas por estudantes e profissionais da educação que estejam em lugares e tempos diversos (BRASIL, 2017, p.1).

Por sua vez, deve-se compreender o Ensino Remoto Emergencial enquanto:

[...] modalidade de ensino ou aula que pressupõe o distanciamento geográfico de professores e estudantes e vem sendo adotada nos diferentes níveis de ensino, por instituições educacionais no mundo todo, em função das restrições impostas pelo COVID-19, que impossibilita a presença física de estudantes e professores nos espaços geográficos das instituições educacionais. (ANTÓNIO MOREIRA; SCHLEMMER, 2020, p. 8).

Assim, evidencia-se que EaD, de fato, não é igual ao ERE, pois aquela demanda preparação, planejamento e não pode ser realizada de forma improvisada como a atual situação da prática implementada. Além disso, a EaD não se refere somente da transposição do presencial para o virtual.

Mesmo sendo algo já discutido há muito tempo, a formação de muitos professores não incluiu o uso das TDIC. Nesse sentido, tornou-se necessário "equipar os professores com as competências necessárias para que eles possam explorar plenamente o potencial das tecnologias digitais" (TAROUCO, 2019, p. 33).

Além disso, o Conselho Nacional de Educação (CNE) enfatiza a necessidade de levar "em consideração o atendimento dos objetivos de aprendizagem e o desenvolvimento das competências e habilidades a serem alcançadas pelos estudantes em circunstâncias excepcionais provocadas pela pandemia" (BRASIL, 2020, p. 23). Porém, há de se valorizar todo o tipo de iniciativa que se tem realizado, por professores ou gestores educacionais, já que "a inovação e criatividade das redes, escolas, professores e estudantes podem apresentar soluções mais adequadas” (BRASIL, 2020, p. 23) para cada contexto nesse momento.

2 TIC Domicílios (CGI.br) é uma pesquisa realizada anualmente que possui o objetivo de mapear o acesso às Tecnologias de informação e Comunicação nos domicílios urbanos e rurais do Brasil e as suas formas de uso por indivíduos de 10 anos de idade ou mais. Disponível em: https://www.cetic.br/pt/pesquisa/domicilios/ 
De forma repentina, os professores tiveram suas atividades de trabalho profundamente alteradas, pois, além de reorganizar as atividades letivas, tanto da Educação Básica (EB) quanto da Educação Superior (ES), é preciso “considerar propostas que não aumentem a desigualdade ao mesmo tempo em que utilizem a oportunidade trazida por novas TDIC para criar formas de diminuição das desigualdades de aprendizado" (BRASIL, 2020, p. 3).

Essa preocupação também está presente nas recomendações publicadas pela UNESCO (2020), dedicadas à efetivação do ensino em decorrência da pandemia. Uma dessas indica a necessidade de "analisar a resposta e escolher as melhores ferramentas", ou seja, considerar o contexto da comunidade escolar e, dessa maneira, encontrar as possibilidades reais, mesmo que não sejam as ideais. Assim, ao propor o ERE surge a necessidade da reorganização das unidades.

Além da definição dos recursos que serão utilizados, é necessário considerar os tipos de comunicação, síncrona ou assíncrona, assim como o tempo de cada atividade, a faixa etária dos aprendizes, avaliar se essas aulas trarão novos conteúdos ou a revisão dos já trabalhados em aulas presenciais, entre outros fatores, os quais também aparecem nas recomendações da UNESCO. Sobre os recursos tecnológicos, esse documento ainda aponta a necessidade de se explorar as possibilidades em poucas plataformas, tendo em vista que a dificuldade de aprender a lidar com dispositivos diferentes pode ser um obstáculo para a efetivação das práticas de ensino e aprendizagem.

O uso das TDIC na educação já é discutido há muito tempo. Existem inúmeras pesquisas que trazem inestimáveis contribuições para o desenvolvimento dessas práticas e compreensão dos processos de ensino e aprendizagem mediados por instrumentos tecnológicos, porém, esse assunto ainda é novo em muitos contextos. Assim sendo, deve-se considerar os recursos disponíveis, aos docentes e alunos, tanto em termos de tecnológicos quanto humanos, como a necessidade de um adulto para auxiliar a criança, no que se refere às habilidades necessárias ao manuseio dos dispositivos, entre outros, pois, conforme Couto, Couto e Cruz (2020, p. 202),

[...] pessoas amparadas financeiramente e com amplo acesso à Internet vivem um isolamento social criativo. Enquanto, as que sobrevivem em situação de vulnerabilidade social e exclusão digital têm muito mais dificuldades para viver o recolhimento e se proteger do contágio de um vírus para o qual ainda não se tem vacina e nem medicamentos.

Portanto, é indispensável analisar cada contexto para "garantir a inclusão", outra orientação da UNESCO, no sentido de possibilitar acesso para todos aqueles que não possuem recursos técnicos necessários e às pessoas com necessidades educacionais específicas, proporcionando condições de equidade e inclusão social.

Nesse mesmo sentido, é necessário "fornecer apoio a professores e pais no uso de tecnologias digitais”, aspecto também componente do documento da UNESCO. Conforme já mencionado, nem todos os professores possuem formação para o uso da TDIC e "o fato de o professor ser usuário de tecnologia não lhe garante a transposição didática” (MODELSKI; GIRAFFA; CASARTELLI, 2019, p. 14), ou seja, "não garante que ele fará uso pedagógico dos seus conhecimentos com seus alunos" (PERRENOUD, 2000, p. 14). 
Na utilização de recursos digitais surgem outros desafios, considerando que "em uma atividade virtual é muito mais difícil prender a atenção do aprendiz e garantir seu envolvimento e participação, mesmo em cursos bem planejados" (TORI, 2017, s.p.). Desse modo, deve-se considerar, além da urgência da implementação do ERE, alguns contextos que enfrentam dificuldades ainda mais evidentes, como é o caso das turmas de alfabetização, da educação infantil, dos alunos com deficiências etc. Nessas situações, os professores precisam contar, ainda mais, com a colaboração dos pais, tanto para o manuseio das ferramentas, quanto para orientar os filhos acerca das atividades propostas.

Assim, "no meio dessa pandemia, os professores estão ensinando, os pais estão ensinando e apoiando o aprendizado, e muitas crianças são responsáveis por seu próprio aprendizado" (ALEXANDER et al., 2020, p. 1). Portanto, é necessário também fornecer apoio aos pais, pois muitas vezes eles não possuem conhecimentos específicos (pedagógicos, tecnológicos etc.) para a realização dessa nova atividade.

Apoio que pode acontecer em forma de dicas e orientações direcionadas com o objetivo de ampará-los para que consigam acompanhar e auxiliar seus filhos na execução das tarefas. Além disso, as famílias podem não ter infraestrutura para manter um ou mais filhos em aulas síncronas on-line ao mesmo tempo, por exemplo. Ademais, para ambos, pais e professores, ainda existe a questão do tempo, pois com o distanciamento físico, em casa, consequentemente, acumulam-se novas tarefas.

\section{PERCURSO METODOLÓGICO}

A presente investigação possui caráter qualitativo e tem como modalidade investigativa a análise narrativa. Bastos e De Andrade Biar (2015, p. 99) definem narrativas como “o discurso construído na ação de se contar histórias em contextos cotidianos ou institucionais, em situações ditas espontâneas ou em situações de entrevistas”. Nesse sentido, busca-se compreender os desafios da educação em tempo de pandemia a partir dos relatos dos professores entrevistados.

A geração de dados deu-se por meio de entrevistas semiestruturadas elaboradas com o intuito de encorajar a emergência de narrativas (BASTOS; DE ANDRADE BIAR, 2015), as quais aconteceram por meio do aplicativo Whatsapp em função do cumprimento do distanciamento físico exigido. A técnica de narrativas é mais apropriada quando o objetivo da pesquisa é sobretudo exploratório, pois "permite ao pesquisador 'aprofundar' em busca de respostas mais detalhadas em que o respondente deva esclarecer o que disse” (GRAY, 2012, p. 299-300).

A população do estudo foi selecionada utilizando-se como estratégia o que Gray (2012, p. 149) denomina por amostragem intencional aleatória, onde, a "partir de um conjunto de opções possíveis, seleciona-se um número limitado aleatoriamente". Os participantes da presente pesquisa foram professores da rede de contato dos pesquisadores, atuantes na educação formal e as entrevistas aconteceram no mês de maio de 2020.

A análise de dados foi realizada por meio de codificação e categorização. 0 processo de codificação gerou três categorias: Estratégias de Enfrentamento e Ferramentas; Apoio aos Professores; Apoio aos Pais. 


\section{NARRATIVAS DA LINHA DE FRENTE DA EDUCAÇÃO: RESULTADOS}

A presente seção apresenta as narrativas dos nove professores participantes da presente investigação. O Quadro 1 traz a sigla utilizada para preservar as identidades dos docentes e um pouco de seus contextos, com o intuito de auxiliar na compreensão dos relatos.

0 trabalho pedagógico na linha de frente da educação durante o momento pandêmico exige dos professores a adoção de estratégias que sejam relevantes dentro de cada contexto de atuação, bem como a escolha por tecnologias, digitais ou não, que estejam disponíveis e possam servir para a efetivação de práticas no ERE. Dessa forma, a primeira categoria deste estudo refere-se justamente a Estratégias de Enfrentamento e Ferramentas.

Quadro 1 - Contextualização Participantes da Pesquisa

\begin{tabular}{|c|c|}
\hline Sigla & Contexto \\
\hline P1 & Professora da Educação Superior de uma instituição pública na região metropolitana de Porto Alegre-RS. \\
\hline P2 & Professora da Educação Superior de uma instituição pública no interior do PR. \\
\hline P3 & Professora da Educação Superior de uma instituição privada no interior do RS. \\
\hline P4 & Professora da Educação Superior de uma instituição privada no interior do PR. \\
\hline P5 & Professora da Educação Básica de uma instituição pública no interior do RS. \\
\hline P6 & Professora da Educação Básica de uma instituição pública no interior do PR. \\
\hline P7 & Professora da Educação Básica de uma instituição pública na capital, Curitiba- PR. \\
\hline P8 & Professor da Educação Básica de uma instituição privada na capital, Porto Alegre-RS. \\
\hline P9 & Professora da Educação Básica de uma instituição privada no interior do PR. \\
\hline
\end{tabular}

Fonte: Dos Autores (2020).

Na instituição em que P1 atua o calendário foi suspenso. Ela disse que os comentários acerca dessa decisão dão a "entender que muitos alunos não têm acesso à educação remota através da internet”. P1 destaca que:

[...] sem dúvida o maior desafio nisso tudo é a EaD. Lidar com as ferramentas digitais, criar atividades em plataformas que a gente não está acostumado e isso gera também um tempo muito maior, de preparação, de planejamento e ainda mais se for uma proposta em grupo, com várias pessoas, com várias limitações, com diferentes ideias. Então, sem dúvida, em termos de educação na pandemia se a gente for colocar só a questão do ensino o problema é o uso das ferramentas, [...] mesmo que, muitas vezes, a gente use a ferramenta Moodle para postar alguma atividade ou solicitar o envio de alguma tarefa, é muito diferente do que a gente está precisando hoje.

No entanto, P1 acredita que, provavelmente, terão que inserir essa modalidade, para retomar o calendário e, depois, pensar em como "trazer $100 \%$ dos estudantes para dentro dessa nova modalidade, dessa nova estrutura, considerando toda a desigualdade social”. 
Também no ensino superior, P2 conta que no início do "isolamento social”, realizaram duas semanas de "atividades acompanhadas" e, posteriormente o calendário letivo foi suspenso. Destaca que ao longo dessas atividades, percebeu duas coisas importantes:

[...] tanto professor quanto aluno ficaram completamente perdidos em relação a essas atividades. Os professores sem ter muita noção do que mandar, da quantidade que mandar e sempre naquele formato de exercício. Então, quando as atividades retornaram, os professores surtaram porque era muita coisa para corrigir e a baixíssima adesão dos alunos em relação àquelas duas semanas.

P2 também salienta que os alunos apontaram problemas relacionados ao acesso à internet e à quantidade elevada de atividades. Comentou, ainda, que no início de maio começaram a trabalhar em alternativas para retomar as atividades remotas, ao menos para algumas disciplinas, que irão considerar as características de cada uma e a questão da adesão dos estudantes com o intuito de "ter um menor número de alunos circulando no campus”, quando as aulas voltarem.

Já a instituição de P3 definiu que as atividades seriam mantidas, porém, realizadas em home office, de forma síncrona e no horário habitual. Enquanto estratégia optou-se pela gravação da aula e disponibilização do link, em Ambiente Virtual de Aprendizagem (AVA) Moodle, para que possa ser assistida em segundo momento, uma vez que o controle de frequência foi abolido. Também passaram a ser realizadas "aulas magnas de cursos via Google Meet (GM) com acesso aberto à população", mesma ferramenta que está sendo utilizada para as aulas.

P3 destaca que, em sua realidade, "todos os alunos têm acesso aos meios digitais" e que "da parte da instituição não há nenhum direcionamento específico sobre limitações técnicas de alunos". Outro fator de grande importância e que representa um desafio é a motivação. P3 afirma que, para "tentar motivar o aluno", "utiliza exemplos próximos da realidade atual, bem como o uso de objetos de aprendizagem lúdicos" e relata que comprou "uma estrutura de DNA para auxiliar nas explicações".

Com o distanciamento social, a instituição de ensino de P4 disponibilizou as "aulas online" pelo AVA. Essa professora salienta que, no início, houve "alguns problemas de conexão e de adaptação", devido ao grande acesso, pois toda a instituição também estava usando. No entanto, em função de especificidades de suas disciplinas, P4 diz que preferiu não usar o sistema para atividades e como estratégia alternativa optou por "passar alguns casos práticos para [os alunos] encaminharem por e-mail". Explica que essa opção se deu em função de que possui "alguns alunos que tem um pouco mais de dificuldade com a tecnologia, que são um pouco mais velhos", dificuldades até mesmo em digitar, necessitando de adaptação em relação ao tempo disponibilizado para a entrega da atividade.

Ademais, como estratégia disponibiliza $p d f$ ou PowerPoint no sistema, com espaços em branco e, na medida em que está avançando na aula, faz anotações ou desenhos com o mouse, pois o sistema permite. Assim, ela relata que mostra exemplos ou vai explicando com objetos que tem em casa, com o uso da câmera. As aulas de P4 
[...] ocorrem exatamente nos mesmos horários das aulas presenciais, [...] eu abro uma sala e todo mundo tem que estar lá nesse horário, é virtual mas é ao vivo. Então eu faço chamada normal, às vezes pelo próprio sistema, às vezes eu chamo eles. E o conteúdo eu tenho feito assim: eu disponibilizo os slides [...] o sistema possibilita gravar as aulas, a instituição não obriga, mas eles deixam para nós como sugestão que tem alguns alunos que ficam com baixa conexão, não conseguem prestar atenção etc.

P5, que dá aulas de Educação Física para crianças da educação infantil ao $5^{\circ}$ ano do ensino fundamental, relatou que o município onde atua tentava implementar desde 2019 um Portal Educacional para acompanhamento dos estudantes, envio de materiais etc. Destaca que, no início dos "estudos domiciliares", tentaram utilizar esse recurso, mas como há pais que não possuem e-mail ou não conseguem utilizar o portal, optaram por criar grupos de WhatsApp (WA) com os pais de cada turma. Para os que não possuem acesso à internet nem ao WA, "a direção tenta ligar para esses pais irem buscar as atividades na escola ou dão um jeito de levar até a casa das crianças para atingir $100 \%$ dos alunos".

A questão do acesso às atividades remotas, realizadas por meio do Google Classroom (GC) - ferramenta adotada na escola de P6 - também foi um desafio. Além disso, destaca que "com a implantação do estudo remoto pelo governo do Paraná, encontraram, além da dificuldade de acesso, muita resistência de pais e alunos para participar efetivamente do processo". Como forma de minimizar a baixa adesão à participação das atividades no GC, P6 trouxe que estão "fazendo material impresso complementar e grupos de WA por turmas". O WA foi “o principal meio de contato", por meio dele tenho orientado os alunos que estão encontrando dificuldades nos conteúdos, repetindo explicações, mostrando outros exemplos e indicando leituras para reforço". Outro desafio apontado por P6 refere-se à

[...] forma como as atividades são colocadas, as avaliações, a interação com os alunos. Está tudo muito amarrado. As mesmas aulas são exibidas para todos os alunos do estado do Paraná. Após cada aula, algumas questões objetivas são colocadas para resolução no GC. Não é para excluir. Podemos adaptar, mas a orientação da equipe pedagógica e do núcleo regional Estadual é não aumentar atividades, só selecionar as mais importantes [...] encontrar uma forma de atender os alunos com dificuldades de aprendizagem que, no caso da matemática, são muitos.

P7 pontuou que a primeira medida foi antecipar as três semanas de recesso escolar que aconteceriam em julho, "para que as equipes da Secretaria Municipal da Educação (SME) pudessem pensar, analisar e organizar o que seria feito na sequência”. P7 faz parte desse grupo de professores e conta que "foi nesse período que iniciamos os estudos para compreender a situação e verificar as possibilidades de um trabalho pedagógico com os estudantes de $1^{\circ}$ ao $5^{\circ}$ ano, a distância. Algo inédito até então!”.

P7 relata que a forma encontrada para manter os estudantes "na ativa, ou seja, em situações de uma possível rotina de aprendizagens estruturadas e organizadas, e que são adquiridas na escola”, foi a gravação e transmissão de videoaulas de educação escolar a distância, as quais "são gravadas uma semana antes de serem exibidas na tv aberta, canal 9.2 (tv cultura) e no Youtube”. Essa escolha 
foi realizada devido ao entendimento que "a tecnologia é uma via de mão dupla: tanto para quem emite, quanto para quem recebe; os dois lados devem estar conectados. Caso contrário, não se atinge os objetivos".

P7 aponta que de início dois grandes desafios se apresentaram no que se refere à gravação e organização das aulas a distância para crianças pequenas, tendo em vista que não possuíam recursos necessários, o que demandou a contratação de uma empresa e era necessário vencer o desafio de como prender a atenção da criança em frente a uma televisão com conteúdo escolar. P7 relata que, na matemática, estão "recorrendo à literatura infantil, jogos, atividades lúdicas, materiais manipuláveis" e optaram "por preparar e gravar as aulas em duplas", contribuindo para "dinamizar a aula e prender um pouco mais a atenção das crianças". Nesse sentido, P7 avalia que "até o momento, essa experiência tem sido bem interessante".

Outro fato relevante relatado por P7 é que a SME de Curitiba fez parceria com o governo do Estado do Paraná, compartilhando as "videoaulas para outros municípios do estado que tenham interesse em usar" e, em contrapartida, "a Secretaria do Estado repassa as videoaulas de $6 .^{\circ}$ ao $9 .^{\circ}$, que eles gravam, para os nossos estudantes” desses anos. Também cabe destacar que a P7 já mostrou organização para retomar o trabalho realizado quando as aulas presenciais voltarem, explicando que "após a gravação de cada aula, as principais atividades desenvolvidas durante as videoaulas, estão sendo transformadas em cadernos", os quais "serão disponibilizados para os professores regentes das escolas".

A escola de P8 adotou "estudos domiciliares" desde a primeira semana de suspensão das atividades presenciais. Inicialmente cada docente tinha liberdade para propor as atividades em diferentes formatos. Nesse caso, P8 começou a gravar videoaulas com apoio de uma TV que servia como projeção do conteúdo, mas destacou que outros professores usaram outros recursos: desde apresentações do PowerPoint à disponibilização de materiais escritos, próprios ou já utilizados pelo colégio. No entanto, um questionário enviado às famílias dos alunos apontou "a questão da desorganização dos estudantes".

Assim, a partir da $6^{\mathrm{a}}$ semana, "a metodologia começou a ficar um pouco mais padronizada” a orientação do colégio foi para "que cada professor trabalhasse com três quartos da sua carga horária com transmissão ao vivo, utilizando uma ferramenta da Microsoft, que é o Teams”.

Portanto, toda "sexta publica-se [...] em um Moodle adaptado [...] as atividades e trabalhos" e tudo ocorre via esse AVA do colégio e "o Teams é utilizado simplesmente para essas lives". Entre os desafios, P8 destaca que existem alguns de ordem técnica "por exemplo, a questão da internet, com a cidade inteira utilizando, então tem oscilações tanto para mim que faço a transmissão quanto para os estudantes que acabam recebendo e a gente tem que mediar também essas situações" e, como alternativa, permite, quando os alunos pedem, gravar as transmissões.

Por sua vez, P9 disse que a primeira estratégia adotada pelo colégio foi a disponibilização de videoaulas gravadas diretamente pela sede da rede privada em que atua, mas "não deu muito certo isso. Estava tendo muita reclamação dos pais, porque eles queriam os professores que eles já estavam habituados". Assim, após duas semanas eles adotaram aulas ao vivo, no mesmo horário das aulas presenciais e "a única diferença é que reduziu o tempo". 
Em sua avaliação, P9 diz que "tem fluído muito bem, agora, esse estilo de aula”, relata que "prepara 'slides', trabalha pela ferramenta GM" e "consegue explicar através do slide como se fosse o quadro e eles conseguem tirar as dúvidas através do chat”, os alunos têm a possibilidade de usar o microfone quando possuem questionamentos e complementa dizendo que "as atividades ocorrem tanto de maneira síncrona, no momento ao vivo e atividades publicadas no GC que eles devolvem como tarefas".

Conforme já mencionado, os professores tiveram que mudar suas práticas da noite para o dia e, considerando que nem todos possuem domínio da TDIC, nem formação nessa direção, o apoio para esses atores faz-se essencial para que o ERE aconteça. Nesse sentido, destacam-se ações relatadas pelos entrevistados relacionadas ao Apoio aos Professores, segunda categoria.

0 relato de $\mathrm{P} 2$ enfatiza a necessidade de apoio aos professores, pois

[...] com exceção de raríssimos que já trabalham com isso, realmente nós não estamos preparados para trabalhar dessa forma, está sendo bem complicado Tem relatos de professores que entraram em pânico quando descobriram que teriam que voltar às aulas online, alguns não sabem nem mexer na ferramenta institucional Moodle. Está sendo bem caótico, aprendemos a duras penas a usar as tecnologias, então não estávamos preparados para isso e ainda não estamos. É esse sentimento que eu vi na última reunião. Não estamos preparados para lidar com tudo isso, para transformar o curso, a mentalidade do professor e a mentalidade do aluno.

P8 diz que o colégio onde atua fornece "assessoria, utilizando um técnico educacional e uma equipe de TI que prontamente resolve ou tira as dúvidas dos professores" e a "coordenação pedagógica se coloca à disposição para qualquer dúvida”. De modo mais específico, P8 destaca o caso de uma professora com mais de setenta anos, que "não era muito adepta da tecnologia" e por isso recebeu atenção maior para aprender a utilizar o Teams e para ministrar aulas síncronas.

A partir da instituição de "aulas remotas" P3 explica que “os professores receberam orientações e tutoriais para a realização das aulas via GM e em relação à disposição de materiais para alunos foi disponibilizado um AVA onde os professores propõem atividades e também avaliações". Da mesma forma, $\mathrm{P} 4$ comenta que o grupo de professores tem recebido

[...] algumas capacitações para poder trabalhar com o sistema online, tem sido um pouco desafiador para todos, porque precisamos reformular algumas coisas, mas vários professores acabam seguindo a mesma metodologia, que é o que o sistema online, por enquanto, permite.

Na capital do Paraná, P7 salientou que os professores da sua área já participavam de formação continuada, mas que, com o isolamento social, ela passou a ser "feita por GM, videochamadas, WA etc., em diversos momentos da semana", com o acompanhamento dos professores.

No mesmo sentido, faz-se necessário fornecer Apoio aos Pais, terceira categoria de análise, que agora assumiram o papel de mediadores pedagógicos, pois precisam auxiliar e acompanhar os filhos na realização das atividades. 
No contexto de P6,

[...] os pais dos alunos menores foram inseridos no grupo de WA das turmas juntamente com os alunos para facilitar o contato. Muitos estão preocupados, entram em contato sempre e fazem o que podem para acompanhar e ajudar seus filhos, outros permanecem no grupo, mas não se manifestam e alguns poucos saíram do grupo logo que inseridos. Para os pais que estão no grupo sempre fazemos orientações direcionadas a eles como a importância de acompanhar os filhos, postamos planilhas das atividades já realizadas e as faltantes para que possam cobrar também. Para os que se retiraram do grupo ou não têm WA, o contato e as orientações ficam a cargo da equipe pedagógica e direção por telefone, recados e até pessoalmente, quando possível.

P6 ainda elenca como desafio "convencer pais e alunos a fazer uso dos meios colocados à disposição [...] para continuidade do processo de aprendizagem”. Nessa mesma direção, P5 explica que, a princípio, mandaram muitas atividades para casa e os pais começaram a reclamar muito, por isso, agora estão "selecionando bem as atividades, para que o aluno consiga entender da forma mais fácil possível para fazer e não precisar tanto da ajuda dos pais”.

P5 enfatiza que um grande desafio é que dependem "totalmente dos pais, porque quem abre, faz o registro, lê e explica as atividades para as crianças são eles”, e acrescenta que algumas famílias têm vários filhos e poucas condições. Para os alunos das turmas de alfabetização, as próprias professoras fazem a entrega do material para tentar orientar os pais, “a cada 15 dias chamam alguém da família para ir, de máscara, em local combinado". P5 ainda conta que "os pais gostam de ajudar os pequeninos", no entanto eles não sabem como, por exemplo, quando P5 enviou "uns vídeos com algumas atividades" os pais estavam fazendo algumas coisas no lugar deles, então ela tentou orientá-los.

P7 explica que "as direções das escolas fazem reuniões com os pais por meio de videoconferência. Dão suporte às famílias, caso alguma delas necessite de algum material escolar para que as crianças possam acompanhar as aulas". Assim como P8, quando diz que "com o isolamento social o colégio deixou bem claro que a prioridade são os estudantes”, e, assim, orientar os pais é papel do próprio colégio. Acrescenta que "tem pais que acompanham as lives dos estudantes, até é orientação do colégio para acompanhar os filhos nesse período", os quais “estão gostando e enviando elogios”. P5 também relata que o feedback positivo dos pais serve como motivação para a continuidade do trabalho.

\section{NARRATIVAS DA LINHA DE FRENTE DA EDUCAÇÃO: DISCUSSÕES}

A condição imposta pela Covid-19 exigiu das instituições mudanças imediatas. Cada professor participante desta pesquisa relata um cenário bem específico e apresenta as ações adotadas até maio de 2020. A partir da análise é possível afirmar que as instituições que conseguiram dar continuidade às atividades letivas têm realizado o que se denomina Ensino Remoto Emergencial (ERE) (BRASIL, 2020), não EaD (BRASIL, 2017), mas que também implica na necessidade de utilização de tecnologias, digitais ou não, bem como exige mediação didático-pedagógica. Foram 
muitos os termos citados nos relatos dos professores para se referirem às atividades letivas realizadas durante a pandemia: "Atividades Acompanhadas" (P2), "Estudos Domiciliares" (P5; P8), “Ensino Remoto Emergencial” (P1; P8), “Educação a Distância” (P1; P4), “Aulas On-line” (P2; P4; P5; P9) e "Aulas Remotas" (P6; P8).

A situação não possibilitou fornecer preparo adequado aos professores (TAROUCO, 2019) para essa nova configuração, visto que não se trata somente da transposição do presencial para o virtual (PERRENOUD, 2000; MODELSKI; GIRAFFA; CASARTELLI, 2019), mas da criação e disponibilização de recursos, os quais são, muitas vezes, diferentes dos utilizados na aula presencial, buscando atender aos objetivos de aprendizagem elencados pelo CNE (BRASIL, 2020).

Alguns professores relataram que receberam orientações das instituições (P2; P3; P4; P7; P8). P5, P6, P7 e P8 também trouxeram a preocupação de orientar os pais dos estudantes para que eles possam apoiar os processos de ensino e aprendizagem. Embora haja elogios, também existem enfrentamentos de situações com as famílias em relação ao convencimento para a utilização das ferramentas, realização das atividades, fornecimento de retorno às escolas, importância da educação etc.

A Quadro 2 apresenta os recursos utilizados pelos entrevistados para a viabilização da nova configuração de educação.

Quadro 2 - Recursos utilizados para viabilizar o ERE

\begin{tabular}{|l|c|c|c|c|c|c|c|c|c|}
\hline \multicolumn{1}{|c|}{ RECURS0 } & P1 & P2 & P3 & P4 & P5 & P6 & P7 & P8 & P9 \\
\hline AVA & & X & X & X & & & & X & X \\
\hline Portal educacional & & & & & X & & & & \\
\hline Google Meet (GM) & & & $\mathrm{X}$ & & & & $\mathrm{X}$ & & $\mathrm{X}$ \\
\hline Google Classroom(GC) & & & & & & $\mathrm{X}$ & & & $\mathrm{X}$ \\
\hline Microsoft Teams & & & & & & & & $\mathrm{X}$ & \\
\hline Aulas Síncronas/vídeochamadas & & & $\mathrm{X}$ & $\mathrm{X}$ & $\mathrm{X}$ & & $\mathrm{X}$ & $\mathrm{X}$ & $\mathrm{X}$ \\
\hline Videoaula & & & & & & & $\mathrm{X}$ & $\mathrm{X}$ & $\mathrm{X}$ \\
\hline WhatsApp (WA) & & & & & $\mathrm{X}$ & $\mathrm{X}$ & $\mathrm{X}$ & & \\
\hline Gravação de videoaulas & & & & & & & $\mathrm{X}$ & $\mathrm{X}$ & \\
\hline Televisão (TV) e Youtube & & & & & & $\mathrm{X}$ & $\mathrm{X}$ & & \\
\hline Material Impresso & & & & & $\mathrm{X}$ & $\mathrm{X}$ & & & \\
\hline PowerPoint/ projeção & & & & $\mathrm{X}$ & & & & $\mathrm{X}$ & $\mathrm{X}$ \\
\hline PDF & & & & $\mathrm{X}$ & & & & & \\
\hline e-mail & & $\mathrm{X}$ & & $\mathrm{X}$ & & & & & \\
\hline Outros vídeos & & & & & $\mathrm{X}$ & & & & \\
\hline Outros objetos/ recursos & & & $\mathrm{X}$ & $\mathrm{X}$ & & & $\mathrm{X}$ & & \\
\hline
\end{tabular}

Fonte: Dos autores (2020). 
A antecipação do recesso escolar no cenário de P7 parece ter contribuído para o planejamento e concretização das ações para a implementação do ERE. Destaca-se também, que de modo geral, os professores das instituições privadas não apontaram grandes problemas em relação ao acesso e utilização de recursos digitais pelos alunos, facilitando, dessa forma, as práticas pedagógicas desse momento. Os professores das instituições públicas relataram mais dificuldades (P1; P2; P5; P6; P7). Temos como exemplos o cenário de P1, onde o ERE ainda não aconteceu e de P2 onde, inicialmente, ofereceram duas semanas de "atividades acompanhadas", suspenderam o calendário e ainda estão estudando uma maneira para sua retomada.

No geral, todos precisaram ter à disposição equipamentos como computadores, notebooks, com webcam e uma internet razoável; transformando-se em produtores e editores de videoaulas, entre outras funções antes não desempenhadas. Durante as entrevistas percebeu-se que todos estavam bastante ocupados com o 'novo normal'. Por fim, pode-se afirmar que os professores estão enfrentando inúmeros desafios e possibilitando, na medida do possível, oportunidades de ensino e aprendizagem.

\section{CONSIDERAÇÕES FINAIS}

Tanto professores quanto alunos devem se tornar produtores de conhecimento e não meros consumidores. 0 problema não está somente no fato da transformação que está ocorrendo em função da pandemia da Covid-19, pois essa necessidade já era evidenciada por demandas de uma escola que precisa superar o modelo de reprodução instituído há séculos, ainda que o desafio ora enfrentado traga a necessidade de novas respostas. Em um breve espaço de tempo, os docentes precisaram demonstrar competências digitais e conhecimentos pedagógicos necessários para um novo modelo de ensino, que se tentava discutir e implementar por meio de estratégias de EaD há anos.

Nesse sentido, evidenciou-se ainda mais a necessidade de formar cidadãos (professores, pais, alunos, todos) para lidar com a incerteza, uma formação voltada ao desenvolvimento de competências que possibilite resolver velhos e novos problemas que exigem conhecimentos cada vez mais inter ou multidisciplinares. É preciso estar aberto à mudança, à inventividade, ao novo e ao desconhecido. Afinal, uma estrutura extremamente pequena, como um vírus, é capaz de modificar a realidade global de forma surpreendentemente rápida.

Por fim, pode-se dizer que os desafios enfrentados pelos docentes envolvem desde dificuldade de acesso e falta de recursos; necessidade da superação de limitações de formação para o uso da TDIC e efetivação de práticas de ensino e aprendizagem em contextos não presenciais adaptadas às suas especificidades (disciplina, recursos, idade dos estudantes, fase de escolarização etc.) que demandam ação de maneira que não exclua estudantes, promovendo equidade e inclusão, ainda, carecem de apoio das instituições, bem como dos pais, os quais, por sua vez, precisam receber suporte dos próprios docentes. Ainda, o professor precisa encontrar alternativas para manter contato com os estudantes, muitas vezes sem opções de internet ou em horários deslocados.

0 presente trabalho não descreve todos os desafios enfrentados pelos professores paranaenses e gaúchos, muito menos os brasileiros, pois sabe-se da diversidade de situações e realidades deste 
país. Mas, é importante mostrar situações concretas e mais uma vez chamar a atenção para o trabalho do professor, pois adaptar-se a toda essa nova situação, por si só, já deveria ser louvável.

No entanto, ainda é preciso lembrar da necessidade de valorizar o trabalho desses profissionais que estão na linha de frente da educação e merecem reconhecimento, homenagens e aplausos. Neste cenário, ainda se mostrou importante considerar as iniciativas que buscam auxiliar os profissionais da educação nesse momento, como a UNESCO e as recomendações aqui supracitadas, além das pesquisas na área da Informática na Educação, que vêm desenvolvendo dispositivos e averiguando possibilidades de ensino e aprendizagem para práticas apoiadas pelas TDIC.

\section{AGRADECIMENTOS}

Agradecemos a Universidade Tecnológica Federal do Paraná pelo apoio com concessão de licença qualificação para a autora Francieli. Agradecemos também, ao Instituto Federal de Educação, Ciência e Tecnologia do Rio Grande do Sul pelo apoio concessão de licença qualificação para a autora Jaqueline.

\section{REFERÊNCIAS}

ALEXANDER, N.; GIBBONS, K.; MARSHALL, S.; RODRIGUEZ, M. C.; SWEITZER, J.; VARMA, K. Implementing Principles of Reimagine Minnesota in a Period of Remote Teaching and Learning. University of Minnesota: Minneapolis Foundation, abr. 2020. Disponível em: https://conservancy. umn.edu/bitstream/handle/11299/212407/Reimagine-COVID19-Response.pdf?sequence=1. Acesso em: 4 jun. 2020.

ANTÓNIO MOREIRA, J.; SCHLEMMER, E. Por um novo conceito e paradigma de educação digital online. Revista UFG, v. 20, n. 26, 13 maio 2020. Disponível em: https://www.revistas.ufg.br/ revistaufg/article/view/63438. Acesso em: 4 jun. 2020.

BASTOS, L. C.; DE ANDRADE BIAR, L. Análise de narrativa e práticas de entendimento da vida social. DELTA: Documentação e Estudos em Linguística Teórica e Aplicada, v. 31, n. 4, 2015. Disponível em: https://www.scielo.br/pdf/delta/v31nspe/1678-460X-delta-31-spe-00097.pdf. Acesso em: 23 maio 2020.

BRASIL. Ministério da Educação. Decreto nº 9.057/ 2017. Brasília, 2017.

BRASIL. Ministério da Educação. Conselho Nacional de Educação. Conselho Pleno. Parecer CNE/CP n 5/2020. Brasília, 2020.

CGI.br - Comitê Gestor da Internet no Brasil. Pesquisa sobre o uso das tecnologias de informação e comunicação nos domicílios brasileiros - TIC Domicílios 2018. Núcleo de Informação e 
Coordenação do Ponto BR. São Paulo: Comitê Gestor da Internet no Brasil, 2019. Disponível em: https://www.cetic.br/media/docs/publicacoes/2/12225320191028-tic_dom_2018_livro_eletronico. pdf. Acesso em: 28 maio 2020.

COUTO, E. S.; COUTO, E. S.; CRUZ, I. M. P. \#FIQUEEMCASA: Educação na Pandemia da Covid-19. Revista Interfaces Científicas Educação: v. 9, n.3, 2020. Disponível em: https://periodicos.set.edu. br/index.php/educacao/article/view/8777. Acesso em: 5 jun. 2020.

CURITIBA. Secretaria Municipal de Educação. Disponível em: https://educacao.curitiba.pr.gov.br/. Acesso em: 5 jun. 2020.

GRAY, D. E. Pesquisa no mundo real. Tradução: Roberto Cataldo Costa, 2. ed. Porto Alegre: Penso Editora, 2012.

MODELSKI, D.; GIRAFFA, L. M. M.; CASARTELLI, A. de. Tecnologias digitais, formação docente e práticas pedagógicas. Educação e Pesquisa, São Paulo, v. 45, 2019. Disponível em: https://www. scielo.br/pdf/ep/v45/1517-9702-ep-45-e180201.pdf. Acesso em: 10 jun. 2020.

PERRENOUD, P. 10 novas competências para ensinar. Porto Alegre: Artmed, 2000.

TAROUCO, L. M. R. Competências Digitais dos Professores. In: Comitê Gestor da Internet no BRASIL (CGI.br). Pesquisa sobre o uso das tecnologias de informação e comunicação nas escolas brasileiras: TIC educação 2018. São Paulo: Comitê Gestor da Internet no Brasil, 2019. Disponível em: https://cetic.br/media/docs/publicacoes/216410120191105/tic_edu_2018_livro_eletronico. pdf. Acesso em: 15 maio 2020.

TORI, R. Educação sem distância: as tecnologias interativas na redução de distâncias em ensino e aprendizagem. 2. ed., São Paulo: Artesanato Educacional, 2017.

UNESCO - Organização das Nações Unidas para a Educação, a Ciência e a Cultura. COVID-19: 10 recomendações para planejar soluções de aprendizagem a distância. 6 março 2020. Disponível em: https://pt.unesco.org/news/covid-19-10-recomendacoes-planejar-solucoes-aprendizagemdistancia. Acesso em: 15 maio 2020.

WHO - World Health Organization. Covid-19 quick links. Disponível em: https://www.who.int/. Acesso em: 10 jun. 2020. 
1 Mestre em Letras; Doutoranda em Informática na Educação na Universidade Federal do Rio Grande do Sul - UFRGS; Licenciada em Letras - Português/Inglês; Professora da Universidade Tecnológica Federal do Paraná - UTFPR-DV. E-mail: francielim@utfpr.edu.br

2 Mestra em Matemática; Doutoranda em Informática na Educação na UFRGS; Licenciada em Matemática; Professora do Instituto Federal de Educação, Ciência e Tecnologia do Rio Grande do Sul - IFRS. E-mail: Jaqueline.molon@ canoas.ifrs.edu.br

3 Doutor e Mestre em Educação; Psicólogo; Professor do Pós-Graduação em Informática na Educação, em Educação e da Faculdade de Educação - UFRGS. E-mail: sergio. franco@ufrgs.br

4 Doutora em Informática na Educação e em Linguística Aplicada; Mestra em Letras; Licenciada em Letras - Português/ Inglês; Professora do Programa de Pós-Graduação em Informática na Educação e do Instituto de Letras - UFRGS. E-mail: patricia.campelo@ufrgs.br

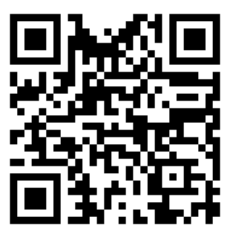

A autenticidade desse artigo pode ser conferida no site https://periodicos. set.edu.br

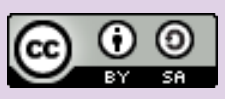

Este artigo é licenciado na modalidade acesso abertosob a Atribuição-Compartilhalgual CC BY-SA

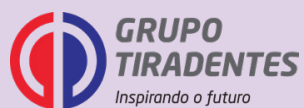

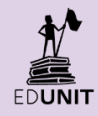

